Fetal Diagnosis and Therapy

\title{
Evaluation of the Utility of in utero Treatment of Twin Anemia-Polycythemia Sequence
}

\author{
Nicolas Sananès ${ }^{a, c}$ Marine Veujoz $^{a}$ Francois Severac $^{b}$ Maël Barthoulot ${ }^{b}$ \\ Nicolas Meyer ${ }^{b}$ Anne-Sophie Weingertner ${ }^{a} \quad$ Monique Kohler $^{a}$ \\ Fernando Guerra $^{\mathrm{a}} \quad$ Adrien Gaudineau $^{\mathrm{a}}$ Israël Nisand ${ }^{\mathrm{a}}$ Romain Favre ${ }^{\mathrm{a}}$ \\ Departments of a Obstetrics and Gynecology and ${ }^{b}$ Public Health, Strasbourg University Teaching Hospitals, and \\ 'INSERM, UMR-S 1121, 'Biomatériaux et Bioingénierie', Strasbourg, France
}

\section{Key Words}

Twin anemia-polycythemia sequence · Twin pregnancy ·

Monochorionic diamniotic twin pregnancy · Laser

coagulation · Fetal transfusion

\begin{abstract}
Objective: The aim of this study is to evaluate the interest in the in utero treatment of twin anemia-polycythemia sequence (TAPS). Methods: The obstetrical and neonatal data on all cases of TAPS followed up in our institution between 2006 and 2013 were reviewed. Statistical analyses were conducted using Bayesian methods. Results: Twenty cases of TAPS were included. Laser therapy or intrauterine transfusion (IUT) was performed on the donor twin in 9 cases. Eleven cases were included in the 'nontreated' group (managed expectantly or diagnosed at birth). The gestational age at diagnosis was lower in the group with treated TAPS [difference (diff) $=-22.20$ days $(-57.13,14.28)$, probability (Pr) (diff $>0)=10.6 \%]$. The rate of preterm premature rupture of membranes was higher in the group with treated TAPS [diff $=22.5 \%(-14,57), \operatorname{Pr}($ diff $>0)=89 \%$, but overall mortality was similar. The interval between diagnosis and delivery was longer [diff $=44.37$ days $(9.41,77.90), \operatorname{Pr}($ diff $>0)=99.2 \%$ ], the TAPS resolution rate was higher [diff $=49.9 \%(12,81)$, $\operatorname{Pr}$
\end{abstract}

(C) 2015 S. Karger AG, Basel

$1015-3837 / 15 / 0383-0170 \$ 39.50 / 0$ (diff $>0)=99.4 \%]$, and the neonatal transfusion rate was lower [diff $=-30.5 \%(-60,0), \operatorname{Pr}($ diff $>0)=2.6 \%$ ] in the treated group. Conclusion: In utero treatment for TAPS is associated with a higher resolution rate of TAPS and a longer time between diagnosis and birth, but overall mortality is the same as with expectant management.

(c) 2015 S. Karger AG, Basel

\section{Introduction}

Twin anemia-polycythemia sequence (TAPS) is a complication of monochorionic diamniotic twin pregnancies first described in 2007 by Lopriore et al. [1]. Its pathology is characterized by an intertwin difference in hemoglobin levels. It may be diagnosed either in the antenatal or the postnatal period and presents a typical angioarchitecture (slender and rather scanty arteriovenous anastomoses) [2]. It is a heterogeneous disorder, both in terms of its mode of onset [either after laser treatment of twin-twin transfusion syndrome (TTTS) or spontaneously] and its severity. There is no consensus about its antenatal management, and different therapeutic alternatives have been described: simple surveillance, intrauterine transfusion (IUT) of the anemic fetus possibly combined with partial

\section{KARGER 125}

E-Mail karger@karger.com www.karger.com/fdt 
Table 1. Pre- and postnatal classification of TAPS [2]

Antenatal stage:

findings at Doppler ultrasound examination

\begin{tabular}{lll}
\hline Stage 1 & $\begin{array}{l}\text { MCA-PSV donor }>1.5 \mathrm{MoM} \text { and } \\
\text { MCA-PSV recipient }<1 \mathrm{MoM} \\
\text { without other signs of fetal compromise }\end{array}$ & $>8.0$ \\
\hline Stage 2 & $\begin{array}{l}\text { MCA-PSV donor }>1.7 \mathrm{MoM} \text { and } \\
\text { MCA-PSV recipient }<0.8 \mathrm{MoM} \text { without other signs of fetal compromise }\end{array}$ & $>11.0$ \\
\hline Stage 3 & As stage 1 or 2 , with cardiac compromise of the donor, defined as critically abnormal flow & $>14.0$ \\
\hline Stage 4 & Hydrops of donor & $>17.0$ \\
\hline Stage 5 & Intrauterine demise of one or both fetuses preceded by TAPS & $>20.0$ \\
\hline
\end{tabular}

MoM = Multiple(s) of the median; $\mathrm{Hb}=$ hemoglobin.

exchange transfusion in the recipient, laser coagulation of the placental anastomoses, selective termination of pregnancy or fetal extraction [2-11]. On account of the low incidence of TAPS $(1-5 \%$ of monochorionic diamniotic twin pregnancies for spontaneous TAPS [12-15] and $2-13 \%$ for iatrogenic TAPS $[4,14-16])$, therapeutic options have been presented only in case reports or smallsize descriptive cohorts. The objective of our study was to examine obstetrical and neonatal outcomes depending on whether or not an antenatal treatment (IUT or laser) had been provided in a series of TAPS.

\section{Materials and Methods}

We carried out a single-center prospective cohort study, with enrollment of all monochorionic diamniotic twin pregnancies complicated by TAPS diagnosed ante- or postnatally and managed at the gynecology and obstetrics hub of the Strasbourg University Teaching Hospitals between December 2006 and August 2013.

The diagnostic criteria for TAPS selected were those drawn up by Slaghekke et al. [2]. In the antenatal period, they associate the absence of twin oligo-polyhydramnios sequence with measurement of a middle cerebral artery peak systolic velocity (MCA-PSV) $>1.5$ multiples of the median in one fetus (anemic, donor) and $<1$ multiple of the median in the other fetus (polycythemic, recipient). The MCA-PSV was measured using the technique described by Mari et al. [17] by means of a Voluson 730 or E8 General Electric ${ }^{\circledR}$ device. In the postnatal period, the diagnosis is based on an intertwin hemoglobin difference of $>8 \mathrm{~g} / \mathrm{dl}$ combined with a reticulocyte ratio of $>1.7$ or the finding of inframillimetric anastomoses. Cases that showed discrepant hemoglobin levels at birth of $>8 \mathrm{~g} / \mathrm{dl}$ but did not meet the other postnatal criteria were also enrolled in the study if there was a strong clinical impression and no evidence of an acute peripartum TTTS [18]. The severity of TAPS was defined using the classification by Slaghekke et al. [2] (table 1).

Evaluation of in utero Treatment of TAPS
The follow-up of each monochorionic diamniotic pregnancy consisted of an ultrasound every 2 weeks. In the case of a diagnosis of TAPS before 32 weeks of gestation (WG), in utero treatment was proposed for TAPS stage 3 or 4 or for TAPS stage 1 or 2 with rapid aggravation. As soon as it had been decided to treat a case antenatally, we opted for fetoscopy with laser coagulation of the placental anastomoses, because this is the only causative treatment. For late cases, and if the technical conditions were not favorable (anterior-lying placenta with anticipated incorrect access of the vascular equator and, consequently, risk of incomplete surgery), IUT was performed. After $32 \mathrm{WG}$, the therapeutic options were expectant management or delivery. Each case was presented at the weekly meetings of the pluridisciplinary prenatal diagnosis center (CPDPN) to validate the in utero management. Two physicians (R.F. and A.-S.W.) performed IUT and laser surgery; they are both well trained in fetoscopic procedures.

The laser photocoagulation technique has already been described in a previous paper [19]. Amnioinfusion was always performed to facilitate access to the vascular equator. The preferred photocoagulation technique was complete coagulation of the vascular equator (Solomon technique) [20,21]. In the case of a technical difficulty, the selective technique was adopted [22]. Follow-up checks of fetal vitality and TAPS status were carried out 24 and 48 $\mathrm{h}$ postoperatively, at 1 week and, superseded by conventional checkups, every 2 weeks. For IUT, the sedation and anesthesia protocol was similar to that followed for laser photocoagulation. The procedure was always carried out with a pediatrician being present. Access was by direct transabdominal needling, with puncture of the umbilical vein at the cord insertion. A 20-gauge needle was used for initial sampling of blood $(5-10 \mathrm{ml})$ to obtain the hemoglobin level. Fetal immobilization was obtained by curarization (Nimbex ${ }^{\circledR}$ at a dose of $0.15 \mathrm{mg} / \mathrm{kg}$ estimated fetal weight). Transfusion was then carried out using leukocyte-free, radiated, CMVnegative, 0 rhesus-negative red cell concentrates compatible with the maternal blood group, the volume being calculated on the basis of the gestational age and initial hemoglobin level. MCA-PSV was checked the day after the procedure, at 7 days and every week to 2 weeks thereafter. 
Fig. 1. Description of the study population. IUFD = Intrauterine fetal demise; $\mathrm{Hb}=$ hemoglobin. * The hematological data on the fetus that was subject to feticide during cesarean section and those on his co-twin were retained for analysis.

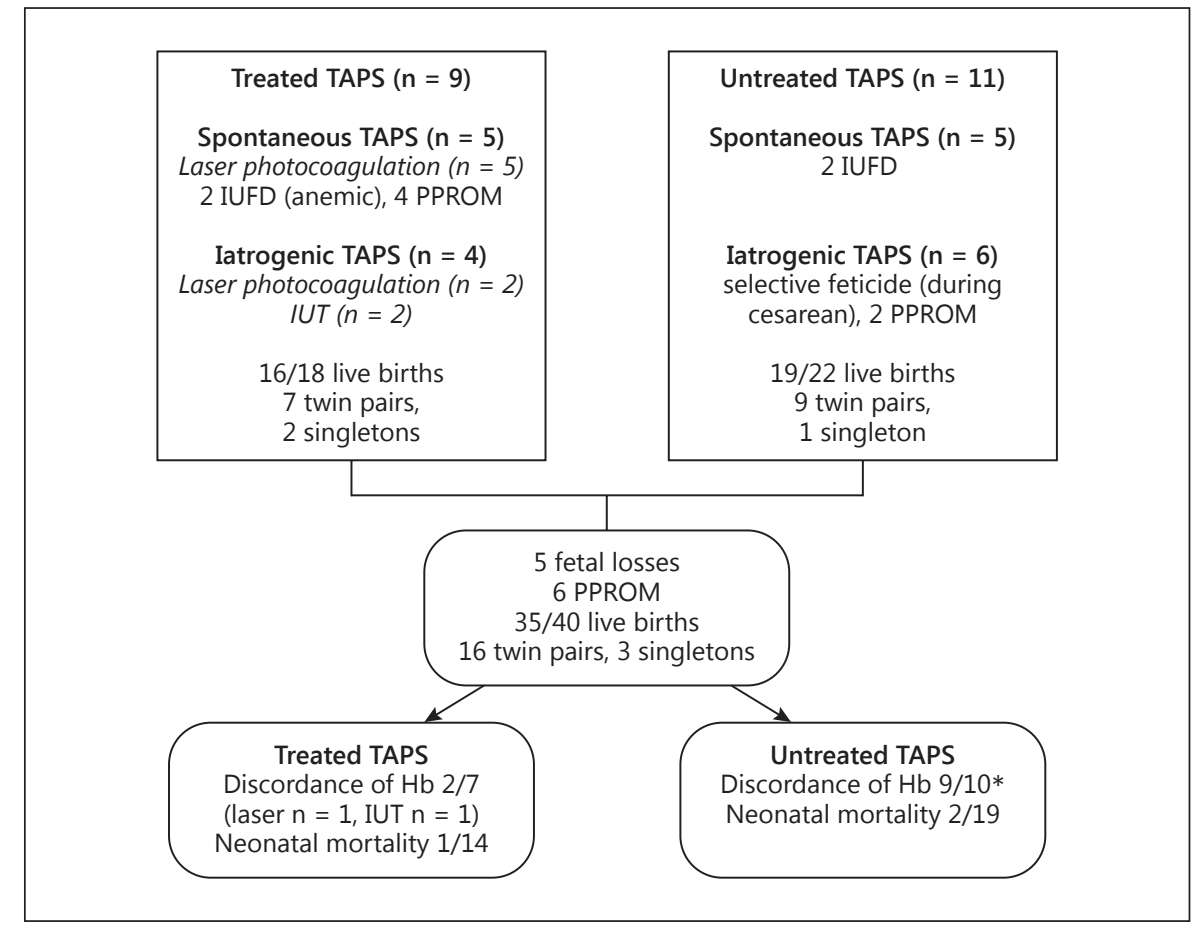

After delivery, photographs of both surfaces of the placenta were taken using a Sony-DSC-W220 digital apparatus (12.1 megapixels) after injection of a coloration dye. The placental weight of each child and the number of arteriovenous anastomoses were gathered.

Data on demographics and antenatal care as well as obstetrical and neonatal outcomes were collected prospectively. The term 'overall mortality' was used to describe the sum of in utero mortality and neonatal mortality (within 28 days of birth). Unequal sharing was defined by a ratio of the weights of the two hemiplacentas of $>1.5$. A difference of $>20 \%$ in weight between the two neonates signaled a birth weight discordance [23]. The data were analyzed and compared between 'treated' TAPS and 'nontreated' TAPS.

Continuous variables are expressed as means $(\mu)$ and standard deviations ( $\sigma$ or SD). Categorical variables are expressed as numbers and percentages. Statistical analyses were conducted using Bayesian methods $[24,25]$ with $\mathrm{R} 3.0 .0$ software and all the required packages in their latest updates at the time of analysis as well as WinBUGS software (estimation using Markov chain Monte Carlo with Gibbs sampling). After a burn-in of 5,000 updates, 100,000 iterations were performed and convergence was checked using trace plots of the sample values for each iteration. Beta distributions $[\mathrm{Be}(\mathrm{a}, \mathrm{b})]$ were used to estimate proportions, while means were estimated using normal distribution $[N(\mu, \sigma)]$. If available, results from previous studies were used to provide informative Bayesian priors. Studies in which some of our cases had already been reported on could not be used as priors to avoid the duplication of data $[6,26]$. In the absence of prior information for the estimation of a proportion, a noninformative $[\mathrm{Be}(1,1)]$ prior was adopted. For the estimation of a mean, the prior was derived from the data (empirical Bayes methods) [27]. The same prior was used for both groups in order to minimize the difference of means.
Each result is presented as a difference (diff) [(result of treated group) - (result of nontreated group)] with a $95 \%$ credibility interval and a probability ( $\mathrm{Pr}$ ) of exceeding 0 (or 1 for an OR). The priors are presented in supplementary table 1 (for all online suppl. material, see www.karger.com/doi/10.1159/000380822). This study received the authorization of the French Commission Nationale de l'Informatique et des Libertés (CNIL) and is registered as No. 1728548.

\section{Results}

Our patient population is described in figure 1. In all, 20 patients developed TAPS during the inclusion period, i.e. a global incidence of $4.6 \%$ was calculated ( 433 patients followed up for monochorionic diamniotic twin pregnancy during the inclusion period); 10 had spontaneous TAPS and 10 iatrogenic TAPS after laser. The diagnosis was made in the antenatal period in 17 cases (85\%) at a mean gestational age of $24.9 \pm 5.9 \mathrm{WG}$. In utero management included laser treatment in 7 cases $(41.1 \%$; 5 photocoagulations using the Solomon technique and 2 selective photocoagulations), IUT in 2 cases (11.8\%), expectant management in 5 cases $(29.4 \%)$, fetal extraction after corticosteroid therapy for pulmonary maturation in 2 cases and as an emergency in 1 case (17.6\%; abnormal fetal heart rhythm in the anemic fetus). The 3 cases diagnosed in the postnatal period were included in the nontreated 
Table 2. Maternal and diagnostic data for comparisons between the treated and the nontreated group

\begin{tabular}{|c|c|c|c|c|c|}
\hline Age, years & $31.1 \pm 2.5$ & $28 \pm 2.8$ & $30.4 \pm 2.8$ & $28.4 \pm 4.7$ & $2.07(-1.46,5.61), 88 \%$ \\
\hline Parity $\geq 1$ & $6(85.7)$ & $2(100)$ & $8(88.8)$ & $3(27.3)$ & $51.1 \%(16,79), 99.7 \%$ \\
\hline BMI & $21.9 \pm 5.2$ & $24 \pm 5.7$ & $22.3 \pm 5.1$ & $24.4 \pm 5.1$ & $-2.04(-6.79,2.76), 18.5 \%$ \\
\hline Iatrogenic TAPS & $2(28.6)$ & $2(100)$ & $4(44.4)$ & $6(54.6)$ & $-8.6 \%(-46,31), 33.3 \%$ \\
\hline \multicolumn{6}{|c|}{ Stage at diagnosis - prenatal } \\
\hline 1 & $3(42.8)$ & $1(50)$ & $4(44.4)$ & $4(36.3)$ & \multirow{4}{*}{$\begin{array}{l}\mathrm{OR}=0.77(0.24,2.41) \\
32.6 \% \text { (prenatal stage })\end{array}$} \\
\hline 2 & $2(28.6)$ & $1(50)$ & $3(33.3)$ & $2(18.2)$ & \\
\hline 3 & $2(28.6)$ & $0(0)$ & $2(22.2)$ & $1(9.1)$ & \\
\hline 4 & $0(0)$ & $0(0)$ & $0(0)$ & $1(9.1)$ & \\
\hline 3 & - & & - & $0(0)$ & - \\
\hline 4 & - & & - & $1(9.1)$ & - \\
\hline
\end{tabular}

Values denote means \pm SD or $\mathrm{n}(\%)$ unless specified otherwise. $\mathrm{BMI}=$ Body mass index; $\mathrm{GA}=$ gestational age; $95 \% \mathrm{CI}=95 \% \mathrm{credibility}$ interval.

group. Of these 3 cases, 2 did not strictly meet all the diagnostic criteria. They were included because the clinical presumption of the diagnosis was strong. Indeed, there was a discrepancy in the hemoglobin levels of $>8 \mathrm{~g} / \mathrm{dl}$, the two-toned placental appearance - which is typical of TAPS [6] - was present, and we found at least 1 arteriovenous anastomosis per placenta. Besides, delivery took place by cesarean section, which does not suggest an indication of acute peripartum transfusion syndrome. Ultimately, 9 cases of TAPS were included in the treated group and 11 in the nontreated group.

The maternal and diagnostic features of TAPS are displayed in table 2 . The obstetrical and neonatal data for the entire cohort are reported in table 3 . Table 4 concerns the subgroup of pregnancies with two live fetuses: 3 cases of pregnancy complicated by intrauterine fetal demise of one or both twins were excluded from the analysis, whereas the weight and hematological data on a twin pair of which the anemic fetus was subject to feticide during cesarean section were retained for the analysis. The gestational age at the time of diagnosis, in the event of antenatal diagnosis, was $23.1 \pm 3.6 \mathrm{WG}$ in treated TAPS versus $27 \pm 7.3 \mathrm{WG}$ in nontreated TAPS, with an estimated difference of $-3.2 \mathrm{WG}$ $(-8.2,2)[\operatorname{Pr}(\operatorname{diff}>0)=10.6 \%]$. The two groups were comparable with regard to the diagnostic stage in the antenatal period as well as the proportion of spontaneous and iatrogenic TAPS. The rate of preterm premature rupture of the membranes (PPROM) was $44.4 \%$ in the treated TAPS group versus $18.2 \%$ in the nontreated TAPS group, with an estimated difference of $22.5 \%(-14,57)[\operatorname{Pr}($ diff $>0)=$ $89.0 \%]$. The mean gestational age at delivery (or miscarriage) was $33.4 \pm 3 \mathrm{WG}$ in the event of treatment versus 30.4 \pm 5.7 WG in the absence of treatment, with an estimated difference of $2.8 \mathrm{WG}(-1.1,6.5)[\operatorname{Pr}($ diff $>0)=92.4 \%]$. The interval between diagnosis and delivery (or miscarriage) was longer for treated TAPS $(10.3 \pm 5.7$ vs. $2.9 \pm 4.1 \mathrm{WG}$ for the other group), with an estimated difference of $6.3 \mathrm{WG}$ $(1.3,11.1)[\operatorname{Pr}($ diff $>0)=99.2 \%]$. At birth, the rate of TAPS resolution was greater in the event of treatment (71.4 vs. $10 \%$ in the absence of treatment), with an estimated difference of $49.9 \%(12,81)[\operatorname{Pr}($ diff $>0)=99.4 \%$, OR $=12.65$ $(1.7,155)]$. In the treated group, the intertwin hemoglobin difference was $6.2 \pm 8.3 \mathrm{~g} / \mathrm{dl}$ (vs. $13.3 \pm 5.6 \mathrm{~g} / \mathrm{dl}$ in the other group), with an estimated difference of $-7.17 \mathrm{~g} / \mathrm{dl}(-14.78$, $0.46)[\operatorname{Pr}(\operatorname{diff}>0)=3.2 \%]$. Transfusion of the anemic infant during hospitalization was necessary in $89 \%$ of the cases in the nontreated TAPS group (vs. $57 \%$ in the treated TAPS group), with an estimated difference of $-30.5 \%(-60,0)[\mathrm{Pr}$ $($ diff $>0)=2.6 \%$, OR $=5.17(0.99,32.34)]$. Overall mortality was $17 \%$ in the treated and $23 \%$ in the nontreated TAPS 
Table 3. Obstetrical data for comparisons between the treated and the nontreated group

\begin{tabular}{|c|c|c|c|c|c|}
\hline GA at birth, WG & $33.9 \pm 3.4$ & $32.1 \pm 1$ & $33.4 \pm 3$ & $30.4 \pm 5.7$ & $2.8(-1.1,6.5), 92.4 \%$ \\
\hline Time between diagnosis and birth, WG & $11.6 \pm 6.4$ & $6.1 \pm 0.3$ & $10.3 \pm 5.7$ & $2.9 \pm 4.1^{\mathrm{a}}$ & $6.3(1.3,11.1), 99.2 \%$ \\
\hline \multicolumn{6}{|l|}{ Live births } \\
\hline Total & $12 / 14(85.7)$ & $4 / 4(100)$ & $16 / 18(89)$ & $19 / 22(86)$ & $-6.6 \%(-19,7), 15.1 \%$ \\
\hline \multicolumn{6}{|l|}{ Overall mortality } \\
\hline Anemic & $3 / 7(42.9)$ & $0 / 2(0)$ & $3 / 9(33)$ & $3 / 11(27)$ & $13.1 \%(-11,36), 86.1 \%$ \\
\hline Polycythemic & $0 / 7(0)$ & $0 / 2(0)$ & $0 / 9(0)$ & $2 / 11(18)$ & $-2.3 \%(-21,15), 40.1 \%$ \\
\hline Total & $3 / 14(21.4)$ & $0 / 4(0)$ & $3 / 18(17)$ & $5 / 22(23)$ & $0(-13,13), 49.6 \%$ \\
\hline
\end{tabular}

Values denote means \pm SD or $\mathrm{n}(\%)$ unless specified otherwise. GA = Gestational age; 95\% CI = 95\% credibility interval.

${ }^{\mathrm{a}} \mathrm{n}=8$; cases diagnosed postnatally excluded.

Table 4. Obstetrical and neonatal data (pregnancies with fetal loss excluded)

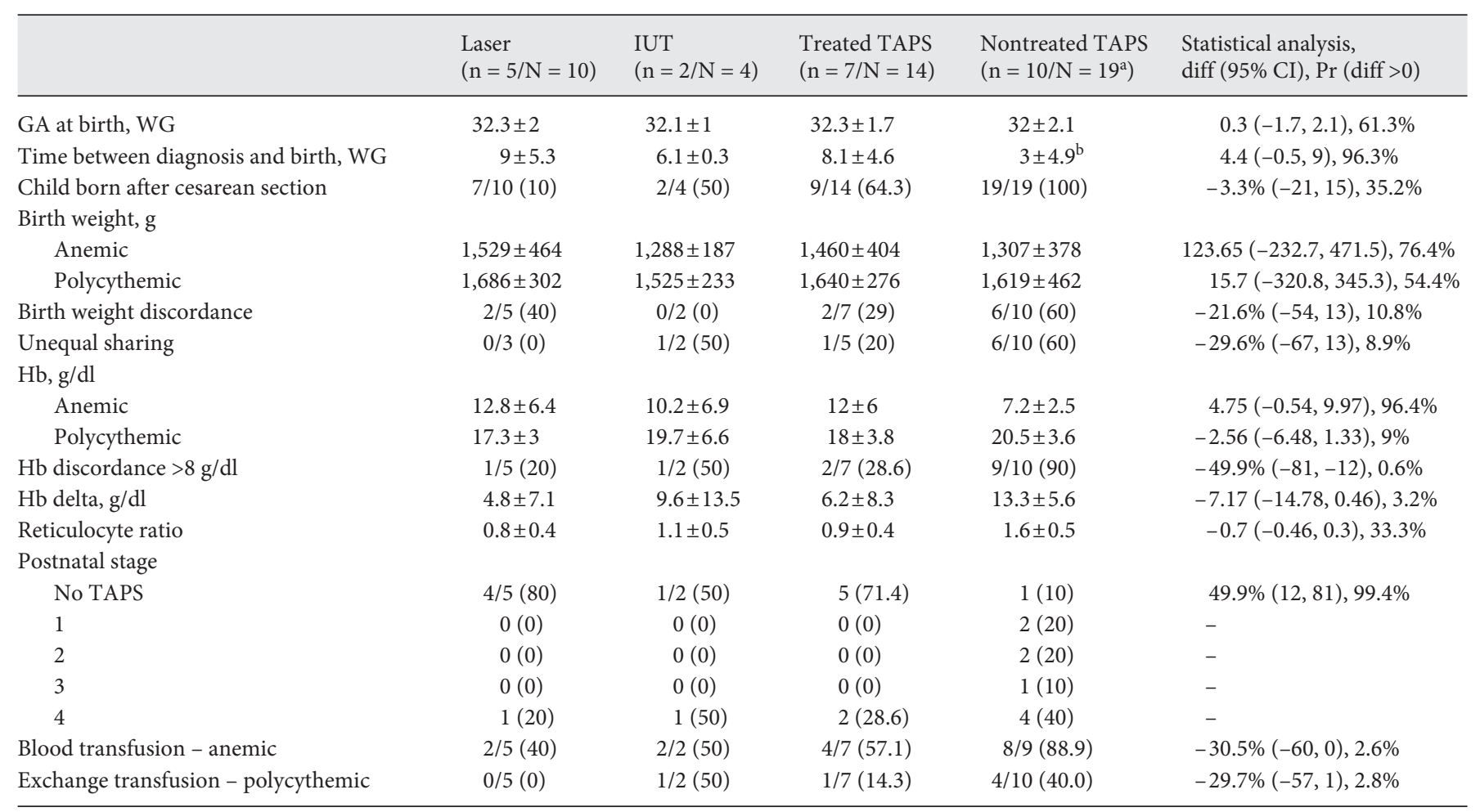

Values denote means \pm SD or $\mathrm{n}(\%)$ unless specified otherwise. $\mathrm{n}=$ Number of cases; $\mathrm{N}=$ number of newborns; $\mathrm{GA}=$ gestational age; Hb = hemoglobin; $95 \% \mathrm{CI}=95 \%$ credibility interval.

${ }^{\text {a }}$ The hematological data and weight of the fetus that was subject to feticide during cesarean section and those of his co-twin were retained for analysis.

${ }^{\mathrm{b}} \mathrm{n}=7$; cases diagnosed postnatally excluded. 

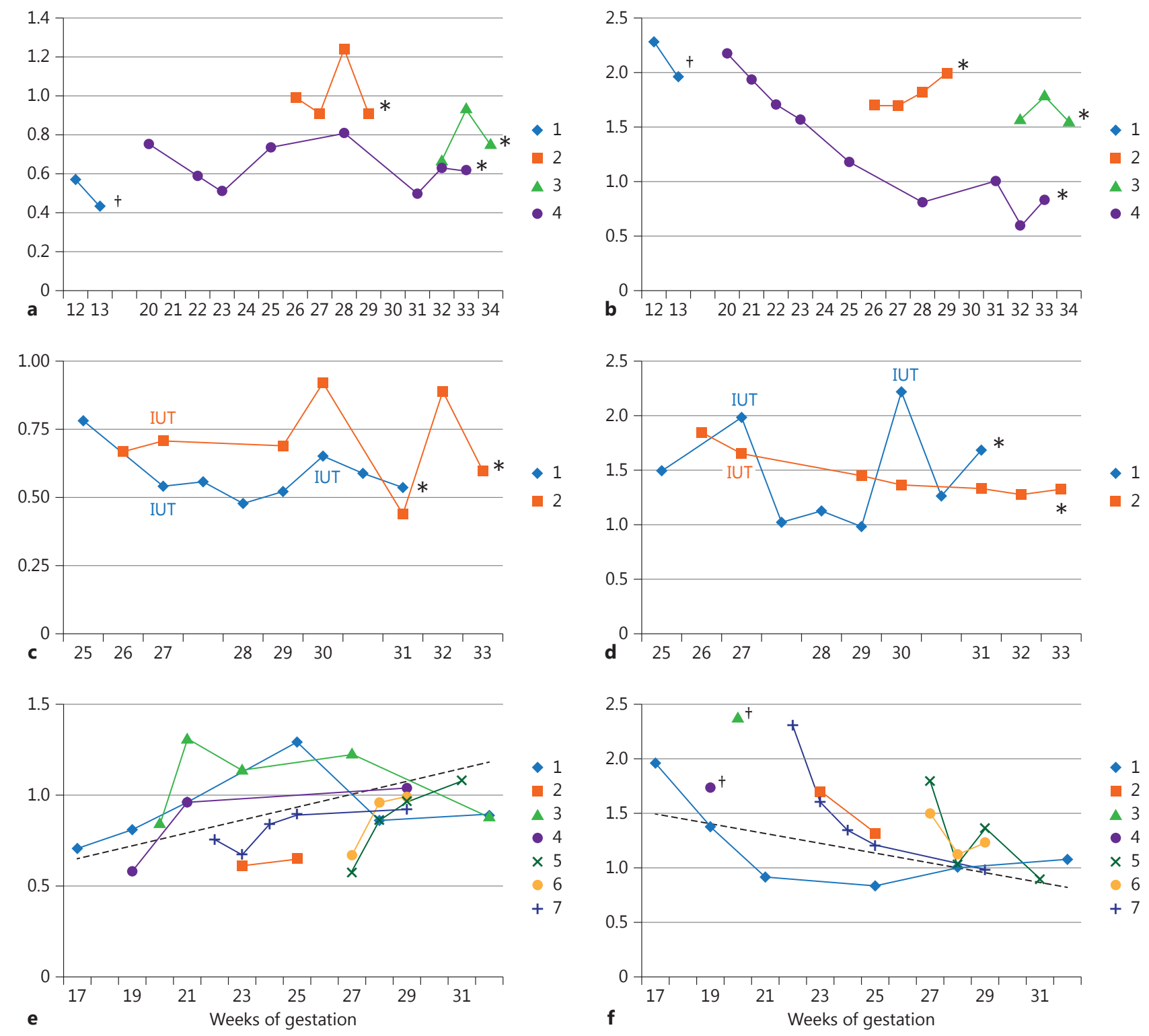

Fig. 2. Evolution of MCA-PSV. a Polycythemic twins in expectant management. b Anemic twins in expectant management. c Polycythemic twins treated with IUT. d Anemic twins treated with IUT. e Polycythemic twins after laser. $\mathbf{f}$ Anemic twins after laser. ${ }^{\dagger}$ Intrauterine fetal demise. ${ }^{*}$ Delivery.

group. A nil estimated difference was retrieved after integration of priors [i.e. the priors pejorated our result; estimated difference $=0 \%(-13,13), \operatorname{Pr}($ diff $>0)=50.4 \%]$.

The changes in MCA-PSV in the polycythemic and anemic fetuses in relation to each therapeutic option (expectant management, IUT or laser) are shown in figure 2. In the expectant management group, the data concern 4 of the 5 cases (a single measurement was made for the fifth case prior to delivery). For the cases treated with laser, the first measurement corresponds to the MCA-PSV before laser treatment. Three patients were referred back to their gynecologist for ongoing surveillance (cases No. 2,4 and 7 ). For the other 4 patients, delivery took place at most 2 weeks after the last measurement. 
Of the 7 cases of TAPS treated with laser, 3 placentas were not exploitable. In 2 cases, maceration occurred due to in utero death of one of the two fetuses. An analysis of the third placenta was impossible because of a fixation error; unfortunately, this was the single case in which there was a difference in hemoglobin level at birth, reflecting a failure of laser photocoagulation. Of the 13 cases of TAPS not treated with laser, 12 placentas could be analyzed (1 case was excluded because of early in utero death of both fetuses). Comparative analysis revealed an absence of residual anastomoses in the 4 cases treated with laser, whereas arteriovenous anastomoses were detected in $75 \%$ of the cases of nontreated TAPS [estimated difference $=$ $54.6 \%(12,84), \operatorname{Pr}(>0)=99.3 \%, \mathrm{OR}=18.48(1.65,665.37)]$.

\section{Discussion}

Our study suggests that antenatal treatment resolves most cases of TAPS and prolongs the interval between diagnosis of TAPS and delivery at the expense of a rise in PPROM. Overall, there was no difference in terms of overall mortality.

As far as we know, there are limited data in the literature that would enable a rigorous evaluation of the utility of antenatal therapy of TAPS; this is due to the rarity of this sequence and the lack of randomized studies. A multicenter study (including some of our data) on the feasibility of laser for treating TAPS has recently been published [26]. Rather than opting for a specific treatment, this study examined the utility of a therapeutic strategy for treating TAPS with laser or IUT depending on local conditions. Indeed, although laser has the advantage of being an etiological treatment, technical conditions are such that it is not always feasible; IUT would then appear to be an alternative, even if it is only a purely symptomatic treatment.

Our study did not show any benefits of antenatal treatment with regard to fetal and neonatal mortality. Nevertheless, we found that in the treated TAPS group, the rate of TAPS resolution was higher, the interval between diagnosis and delivery was longer, and the gestational age at delivery was more advanced. In addition, the intertwin hemoglobin difference at birth was less marked, and recourse to postnatal hematological treatments was less frequent. There also was birth weight discordance in more than half of the nontreated TAPS cases, whereas this affected only $29 \%$ of the treated TAPS cases. Zhao et al. [28], too, found a more marked tendency towards discrepant birth weights in the event of TAPS versus uncomplicated monochorionic diamniotic twin pregnancies. Correction of anemia therefore appears to be associated with improved growth of the anemic fetus. Nevertheless, birth weight discordance could also be a consequence of unequal sharing, which was more frequent in nontreated TAPS. We did not study the neurological development of these infants, but it should be noted that neurological lesions have been reported in both anemic [5] and polycythemic fetuses $[29,30]$.

Performing an in utero procedure was associated with an increased risk of PPROM: this reflects the iatrogenicity associated with any invasive therapeutic act. Nevertheless, the gestational age at delivery was higher if antenatal treatment was provided. It is noteworthy that none of the 4 patients in our series who underwent two invasive procedures (laser for TTTS and laser or transfusion for TAPS) had PPROM.

The laser procedure is the only etiological treatment, as shown by the graphs which display modifications in MCA-PSV and by placental analysis. In a recent study by Slaghekke et al. [26] on the effect of laser photocoagulation on TAPS $(\mathrm{n}=8)$ as compared to no treatment $(\mathrm{n}=$ 27 ) or IUT ( $\mathrm{n}=17)$, the survival rate after laser was $94 \%$ (vs. 83 and $84 \%$ with expectant management and IUT, respectively; $p=0.30$ ), with a prolonged diagnosis-delivery interval (11 vs. 5 and 8 WG; $\mathrm{p}<0.01$ ) and no severe hematological complications (vs. 72 and 52\%; p < 0.01). It should be noted that placental photocoagulation for TAPS is more complicated than for TTTS due to the absence of polyhydramnios, a less tense uterine wall, more opaque amniotic fluid as well as slender and often marginal anastomoses $[6,28]$. In the particular case of iatrogenic TAPS after laser treatment, the rationale for repeating the laser procedure should be carefully considered; if the anastomoses were not visualized during the first laser treatment for TTTS, it is unlikely that they will be identified any better during a second procedure. Changing the access route may be helpful, since it may be easier to visualize persisting anastomoses from a different viewpoint. In any event, if a laser treatment is performed, the Solomon technique should be preferred insofar as it is feasible [21].

IUT is a symptomatic treatment, and it sometimes needs to be repeated; this was the case with one of our patients. Study of the MCA-PSV changes illustrates that TAPS recurs at some point following the procedure. However, one of our cases presented a less typical progress, with resolution of TAPS following IUT and no relapse. A similar case was described by Robyr et al. [4]. Absence of anastomosis on placental analysis may sug- 
gest an anastomotic thrombosis, as has been suggested by Lopriore et al. [31]. In any event, IUT should be preferred in cases of TAPS occurring at a later stage, in order to avoid (if possible) having to repeat this procedure. In our cohort, it is noteworthy that the MCA-PSV readings in the recipient fetuses did not show any significant postprocedural modifications, although increased polycythemia is a complication commonly described with IUT and it may give rise to complications [4], especially of a neurological type [32]. Some authors have described partial exchange transfusion of the polycythemic fetus to be associated with IUT of the anemic twin, with the advantage of reducing the potential risk of complications due to polycythemia. However, this procedure is symptomatic and requires double needling [5]. Expectant management is part of the armamentarium for selected cases [8]. A very early case of TAPS, i.e. inaccessible to any in utero therapy, ought to be monitored before any decision is made in order to perform the appropriate procedure at the appropriate time. In our cohort, the course was unfavorable, with double intrauterine fetal demise at $14 \mathrm{WG}$, underlining the considerable prognostic variability of this disorder. A slowly progressing stage 1 or 2 TAPS, especially if diagnosed after $30 \mathrm{WG}$, may also benefit from closer monitoring at least twice monthly or even weekly, as has recently been proposed by our team [33], with antenatal corticosteroid therapy and fetal extraction at what seems to be the right time $[7,34]$. Finally, the decision to proceed with fetal extraction should be discussed after 32 WG whenever there is recurrence or worsening of TAPS. Selective feticide or termination of pregnancy can be considered as a therapeutic option for the more severe cases.

The observational design of our study introduced a potential bias into our analysis, since TAPS cases receiving antenatal treatment are not necessarily comparable with TAPS cases for which expectant management has been selected. There was no difference between the groups with regard to grade of severity, but TAPS cases undergoing in utero treatment were those occurring earliest in pregnancy. It would therefore appear that our study minimized the utility of an antenatal treatment strategy, since those cases treated were the most severe. The size of our cohort was limited, but nonetheless relatively large in view of the incidence of TAPS. Small-size samples generally provide little information. Our Bayesian approach, integrating some previously published data into the priors, would therefore appear to be of particular relevance.

In conclusion, antenatal treatment appears to be an option for selected cases of TAPS even if there is no evidence that it improves overall (fetal and neonatal) mortality rates. Laser photocoagulation of the placenta is the sole etiological treatment, but IUT may be considered if there are technical difficulties. Studies are needed to investigate the neurodevelopmental effects of in utero intervention.

\section{References}

1 Lopriore E, Middeldorp JM, Oepkes D, Kanhai $\mathrm{HH}$, Walther FJ, Vandenbussche FP: Twin anemia-polycythemia sequence in two monochorionic twin pairs without oligopolyhydramnios sequence. Placenta 2007;28: $47-51$.

-2 Slaghekke F, Kist WJ, Oepkes D, Pasman SA, Middeldorp JM, Klumper FJ, et al: Twin anemia-polycythemia sequence: diagnostic criteria, classification, perinatal management and outcome. Fetal Diagn Ther 2010;27:181190.

3 Herway C, Johnson A, Moise K, Moise KJ Jr: Fetal intraperitoneal transfusion for iatrogenic twin anemia-polycythemia sequence after laser therapy. Ultrasound Obstet Gynecol 2009;33:592-594.

-4 Robyr R, Lewi L, Salomon LJ, Yamamoto M, Bernard J-P, Deprest J, et al: Prevalence and management of late fetal complications following successful selective laser coagulation of chorionic plate anastomoses in twin-totwin transfusion syndrome. Am J Obstet Gynecol 2006;194:796-803.
5 Genova L, Slaghekke F, Klumper FJ, Middeldorp JM, Steggerda SJ, Oepkes D, et al: Management of twin anemia-polycythemia sequence using intrauterine blood transfusion for the donor and partial exchange transfusion for the recipient. Fetal Diagn Ther 2013; 34:121-126.

6 Weingertner AS, Kohler A, Kohler M, Bouffet N, Hunsinger MC, Mager C, et al: Clinical and placental characteristics in four new cases of twin anemia-polycythemia sequence. Ultrasound Obstet Gynecol 2010;35:490494.

7 Groussolles M, Sartor A, Connan L, Vayssière C: Evolution of middle cerebral artery peak systolic velocity after a successful laser procedure for iatrogenic twin anemia-polycythemia sequence. Ultrasound Obstet Gynecol 2012;39:354-356.

-8 Fratelli N, Prefumo F, Zambolo C, Zanardini C, Fichera A, Frusca T: Conservative management in a case of iatrogenic twin anemiapolycythemia sequence. Ultrasound Obstet Gynecol 2012;39:597-598.
9 Sainz JA, Romero C, García-Mejido J, Soto F, Turmo E: Analysis of middle cerebral artery peak systolic velocity in monochorionic twin pregnancies as a method for identifying spontaneous twin anaemia-polycythaemia sequence. J Matern Fetal Neonatal Med 2013; 27:1174-1176.

10 Ishii K, Hayashi S, Mabuchi A, Taguchi T, Yamamoto R, Murata M, et al: Therapy by laser equatorial placental dichorionization for early-onset spontaneous twin anemia-polycythemia sequence. Fetal Diagn Ther 2014;35: 65-68.

11 Diehl W, Glosemeyer P, Tavares De Sousa M, Hollwitz B, Ortmeyer G, Hecher K: Twin anemia-polycythemia sequence in a case of monoamniotic twins. Ultrasound Obstet Gynecol 2013;42:108-111.

$>12$ Lewi L, Jani J, Blickstein I, Huber A, Gucciardo L, Van Mieghem T, et al: The outcome of monochorionic diamniotic twin gestations in the era of invasive fetal therapy: a prospective cohort study. Am J Obstet Gynecol 2008;199: 514.e1-e8. 
13 Gucciardo L, Lewi L, Vaast P, Debska M, De Catte L, Van Mieghem T, et al: Twin anemia polycythemia sequence from a prenatal perspective. Prenat Diagn 2010;30:438-442.

-14 De Villiers SF, Slaghekke F, Middeldorp JM, Walther FJ, Oepkes D, Lopriore E: Placental characteristics in monochorionic twins with spontaneous versus post-laser twin anemiapolycythemia sequence. Placenta 2013;34: 456-459.

-15 Nakayama S, Ishii K, Kawaguchi H, Hayashi S, Hidaka N, Murakoshi T, et al: Perinatal outcome of monochorionic diamniotic twin pregnancies managed from early gestation at a single center. J Obstet Gynaecol Res 2012; 38:692-697.

16 Habli M, Bombrys A, Lewis D, Lim F-Y, Polzin W, Maxwell R, et al: Incidence of complications in twin-twin transfusion syndrome after selective fetoscopic laser photocoagulation: a single-center experience. Am J Obstet Gynecol 2009;201:417.e1-e7.

-17 Mari G, Deter RL, Carpenter RL, Rahman F, Zimmerman R, Moise KJ Jr, et al: Noninvasive diagnosis by Doppler ultrasonography of fetal anemia due to maternal red-cell alloimmunization. N Engl J Med 2000;342:9-14.

18 Lopriore E, Holtkamp N, Sueters M, Middeldorp JM, Walther FJ, Oepkes D: Acute peripartum twin-twin transfusion syndrome: incidence, risk factors, placental characteristics and neonatal outcome. J Obstet Gynaecol Res 2014;40:18-24.

19 Lecointre L, Sananès N, Weingertner AS, Kohler M, Guerra F, Fritz G, et al: Fetoscopic laser coagulation for twin-twin transfusion syndrome before 17 weeks' gestation: laser data, complications and neonatal outcome. Ultrasound Obstet Gynecol 2014;44:299-303.
20 Lopriore E, Slaghekke F, Middeldorp JM, Klumper FJ, Oepkes D, Vandenbussche FP: Residual anastomoses in twin-to-twin transfusion syndrome treated with selective fetoscopic laser surgery: localization, size, and consequences. Am J Obstet Gynecol 2009; 201:66.e1-e4.

21 Slaghekke F, Lopriore E, Lewi L, Middeldorp JM, van Zwet EW, Weingertner AS, et al: Fetoscopic laser coagulation of the vascular equator versus selective coagulation for twinto-twin transfusion syndrome: an open-label randomised controlled trial. Lancet 2014;383: 2144-2151.

22 Quintero RA, Comas C, Bornick PW, Allen $\mathrm{MH}$, Kruger M: Selective versus non-selective laser photocoagulation of placental vessels in twin-to-twin transfusion syndrome. Ultrasound Obstet Gynecol 2000;16:230-236.

23 Fick AL, Feldstein VA, Norton ME, Wassel Fyr C, Caughey AB, Machin GA: Unequal placental sharing and birth weight discor dance in monochorionic diamniotic twins Am J Obstet Gynecol 2006;195:178-183.

24 Ntzoufras I: Bayesian Modeling Using WinBUGS. Wiley, 2009.

25 Freedman L: Bayesian statistical methods. BMJ 1996;313:569-570.

26 Slaghekke F, Favre R, Peeters SHP, Middeldorp JM, Weingertner AS, van Zwet EW, et al: Laser surgery as a management option for twin anemia-polycythemia sequence. Ultrasound Obstet Gynecol 2014;44:304-310.

27 Carlin BP, Louis TA: Bayes and Empirical Bayes Methods for Data Analysis, ed 2. Boca Raton, Chapman and Hall/CRC, 2000.
8 Zhao DP, de Villiers SF, Slaghekke F, Walther FJ, Middeldorp JM, Oepkes D, et al: Prevalence, size, number and localization of vascular anastomoses in monochorionic placentas. Placenta 2013;34:589-593.

29 Luminoso D, Figueira CO, Marins M, Peralta CFA: Fetal brain lesion associated with spontaneous twin anemia-polycythemia sequence. Ultrasound Obstet Gynecol 2013;42:721-722.

30 Lopriore E, Slaghekke F, Kersbergen KJ, de Vries LS, Drogtrop AP, Middeldorp JM, et al: Severe cerebral injury in a recipient with twin anemia-polycythemia sequence. Ultrasound Obstet Gynecol 2013;41:702-706.

31 Lopriore E, Hecher K, Vandenbussche FP, van den Wijngaard JPHM, Klumper FJ, Oepkes D: Fetoscopic laser treatment of twinto-twin transfusion syndrome followed by severe twin anemia-polycythemia sequence with spontaneous resolution. Am J Obstet Gynecol 2008;198:e4-e7.

32 Slaghekke F, van Klink JMM, Koopman HM, Middeldorp JM, Oepkes D, Lopriore E: Neurodevelopmental outcome in twin anemia polycythemia sequence after laser surgery for twin-twin transfusion syndrome. Ultrasound Obstet Gynecol 2014;44:316-321.

33 Favre R, Koch A, Weingertner AS, Sananès N, Trieu NT, Kohler M, et al: Vascular pattern in monochorionic placentas with spontaneous TAPS and TTTS with residual anastomoses after laser: a case-control study. Prenat Diagn 2013;33:979-982.

34 Lopriore E, Deprest J, Slaghekke F, Oepkes D, Middeldorp JM, Vandenbussche FP, et al: Placental characteristics in monochorionic twins with and without twin anemia-polycythemia sequence. Obstet Gynecol 2008;112: 753-758. 